\title{
The Ares I-1 Flight Test-Paving the Road for the Ares I Crew Launch Vehicle
}

\author{
Stephan R. Davis, Manager, and Michael L. Tinker, Work Package Manager \\ Flight and Integrated Test Office \\ Exploration Launch Projects Office \\ Marshall Space Flight Center \\ Huntsville, AL 35812 \\ Meg Tuma, Ground Vibration Test Lead \\ Flight and Integrated Test Office \\ Exploration Launch Projects Office \\ Marshall Space Flight Center \\ Huntsville, AL 35812
}

\begin{abstract}
In accordance with the U.S. Vision for Space Exploration and the nation's desire to again send humans to explore beyond Earth orbit, NASA has been tasked to send human beings to the moon, Mars, and beyond. ${ }^{1}$ It has been 30 years since the United States last designed and built a human-rated launch vehicle. NASA is now building the Ares I crew launch vehicle, which will loft the Orion crew exploration vehicle into orbit, and the Ares $V$ cargo launch vehicle, which will launch the Lunar Surface Access Module and Earth departure stage to rendezvous Orion for missions to the moon. ${ }^{2}$ NASA has marshaled unique resources from the government and private sectors to perform the technically and programmatically complex work of delivering astronauts to orbit early next decade, followed by heavy cargo late next decade. Our experiences with Saturn and the Shuttle have taught us the value of adhering to sound systems engineering, such as the "test as you fly" principle, while applying aerospace best practices and lessons learned. If we are to fly humans safely aboard a launch vehicle, we must employ a variety of methodologies to reduce the technical, schedule, and cost risks inherent in the complex business of space transportation.
\end{abstract}

During the Saturn development effort, NASA conducted multiple demonstration and verification flight tests to prove technology in its operating environment before relying upon it for human spaceflight. Less testing on the integrated Shuttle system did not reduce cost or schedule. NASA plans a progressive series of demonstration (ascent), verification (orbital), and mission flight tests to supplement ground research and high-altitude subsystem testing with real-world data, factoring the results of each test into the next one. In this way, sophisticated analytical models and tools, many of which were not available during Saturn and Shuttle, will be calibrated and we will gain confidence in their predictions, as we gain hands-on experience in operating the first of two new launch vehicle systems.

The Ares I-1 flight test vehicle (FTV) will incorporate a mix of flight and mockup hardware, reflecting a configuration similar in mass, weight, and shape (outer mold line or OML) to the operational vehicle. It will be powered by a four-segment reusable solid rocket booster (RSRB), which is currently in Shuttle inventory, and will be modified to include a fifth, inert segment that makes it approximately the same size and weight as the fivesegment RSRB, which will be available for the second flight test in 2012. The Ares I-1 vehicle configuration is shown in Figure 1.

Each test flight has specific objectives appropriate to the design analysis cycle in progress. The Ares I-1 demonstration test, slated for April 2009, gives NASA its first opportunity to gather critical data about the flight dynamics of the integrated launch vehicle stack, understand how to control its roll during flight, and better characterize the severe stage separation environment that the upper stage will experience during future operational flights. NASA also will begin the process of modifying the launch infrastructure and fine-tuning ground and mission operational scenarios, as NASA transitions from the Shuttle to the Ares/Orion system. 


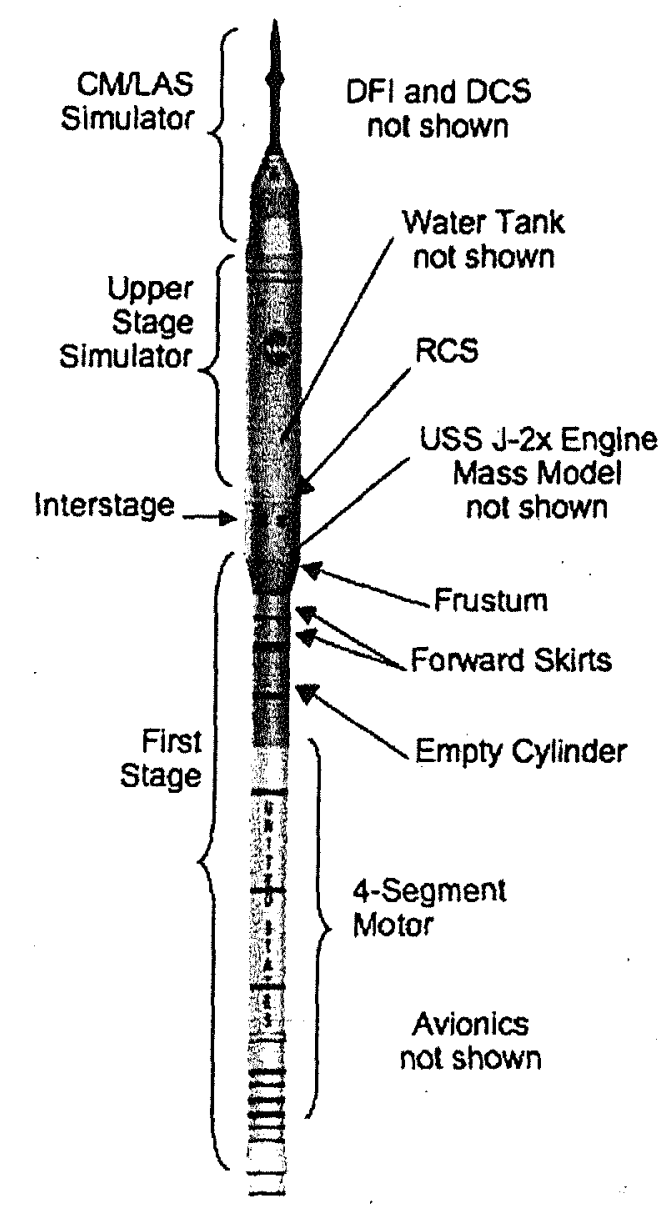

Figure 1. Ares I-1 Flight Test Vehicle Configuration

After liftoff from Kennedy Space Center (Figure 2), the Ares I-1 flight profile will closely mimic the flight conditions the launch vehicle experiences through Mach 4.5 and at an altitude of approximately 250,000 feet through the maximum dynamic pressure quotient (Max Q) of nearly 800 pounds per square foot. Mission elapsed time for first-stage burnout and upper stage separation will be closely matched (within a few seconds), at about 130 seconds into flight. The upper-stage simulator and the Orion Command Module/Launch Abort System (LAS) simulator hardware will then separate from the first stage. The simulator hardware will then fall into the Atlantic; it will not be retrieved. The first-stage booster will then "fly" through a complete recovery sequence, and the hardware will be retrieved and analyzed. After recovery, the first stage hardware will be returned to the Kennedy Space Center (KSC) for inspections and analysis. The data generated will provide information on which to base hardware and software design decisions, as well as to fine-tune operations processes and products. 


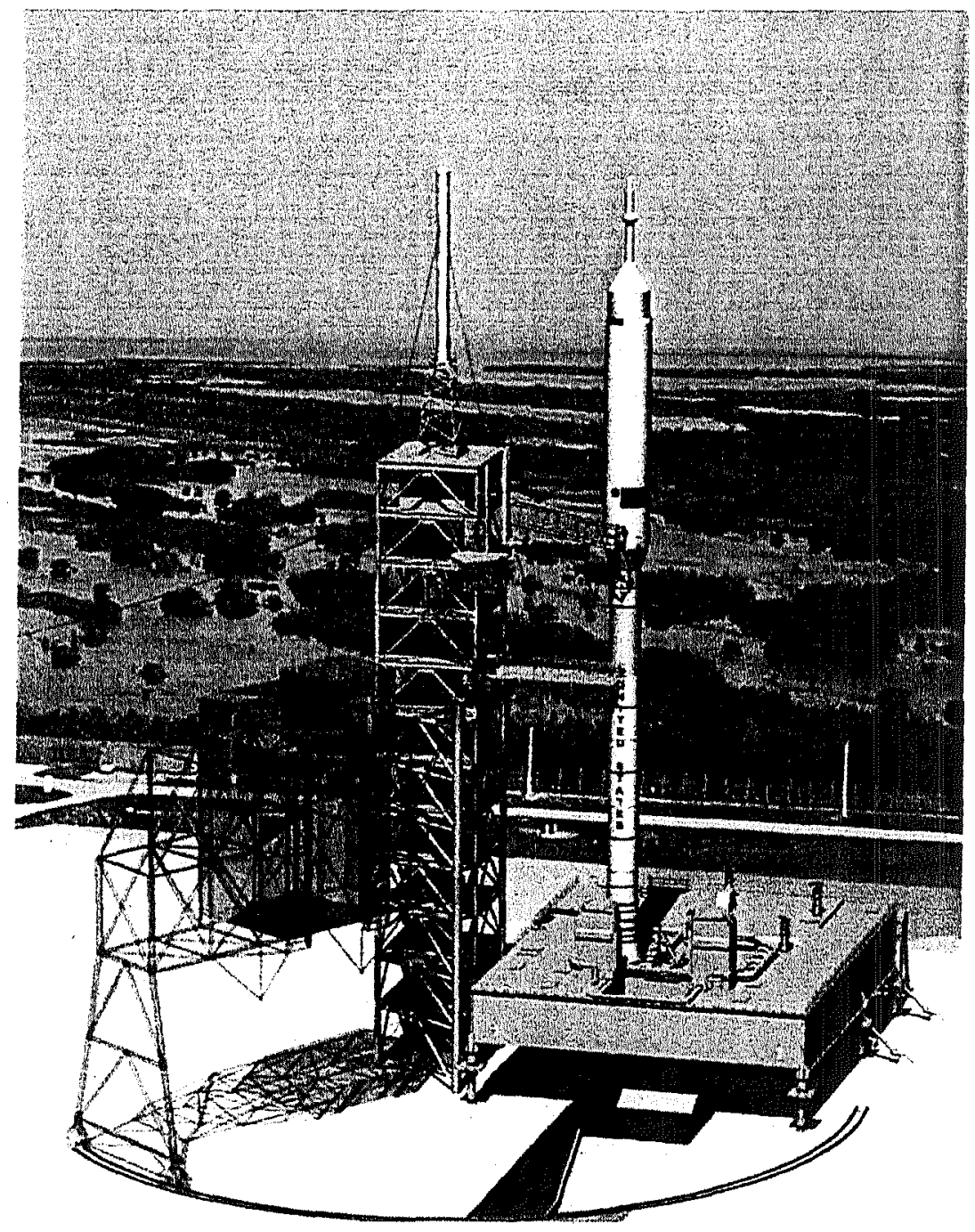

Figure 2. Ares I-1 Flight Test Vehicle at Kennedy Space Center Launch Complex 39

The specific, primary test objectives for the Ares I-1 flight (Figure 3) include:

- Demonstrating the ascent flight control system performance with dynamically similar hardware.

- Characterizing and mitigating the roll torque due to first stage motor performance for a vehicle that is dynamically similar to the operational vehicle.

- Demonstrating nominal first and upper stage separation and clearances.

- Testing the first-stage parachute recovery system and separation/entry dynamics.

- Validating assembly and processing flow, as well as launch and recovery operations.

- Understanding the flight dynamics of the integrated stack.

Once development models of the Orion spacecraft are available for testing on flights after Ares I-1, they will demonstrate the following test objectives with each ascent and orbital flight from KSC:

- Safe separation from the launch vehicle.

- Safe abort distance from the launch vehicle.

- Stability and control of the system, from abort initiation to parachute deployment. 
- Proper Launch Abort System, parachute, and landing system sequencing/procedures.

- Human factor loads in crew area during abort scenario.

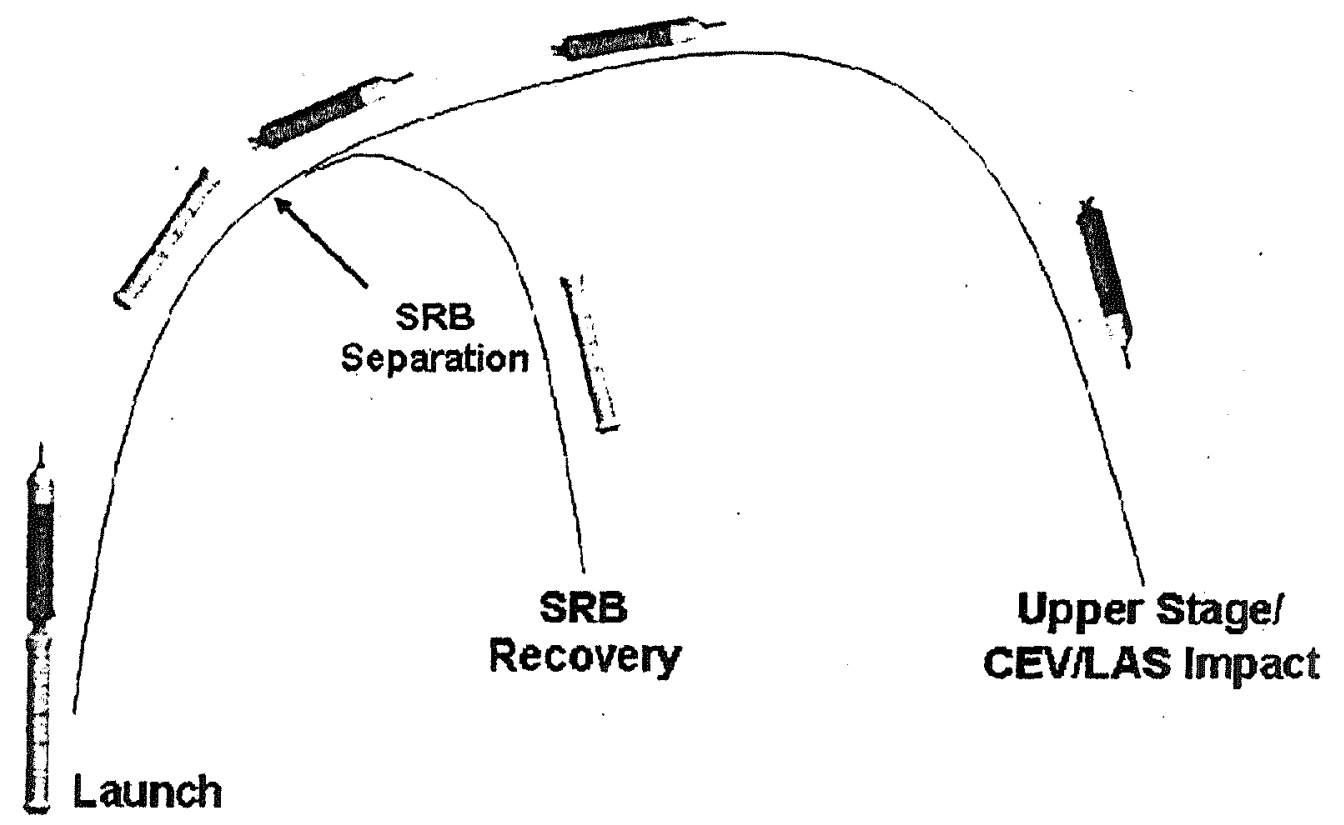

Figure 3. Ares I-1 Flight Test Profile

This important demonstration uses an innovative approach to gathering information prior to the Ares I Critical Design Review, which follows in late 2009. Constellation's flight-testing strategy ensures that the system is safe and fully operational before astronauts begin traveling into orbit via the Ares I crew launch vehicle. Dual-use testing, such as the recent parachute flights of the Ares I first-stage RSRB and the Orion capsule return-to-Earth recovery systems, is integral to ensuring both economy and safety. ${ }^{3}$ In this vein, the crew-escape and survival systems are being tested at specialized ground testing facilities to prepare for the Ares I-1 mission and subsequent test flights.

To engineer America's next fleet of spacecraft, the Constellation team must maximize safety, reliability, and operability for missions to the International Space Station and for the nation's lunar explorations in preparation for much longer journeys and the first human footprint on Mars. This paper includes a brief overview of Constellation ground study methodologies, with objectives founded on the risk-based design and analysis systems engineering approach. Examples illustrate how design tools and processes are being marshaled to reduce the risks that could most impact mission success.

Basing vehicle design refinements on Ares I-1 information puts us one step closer to the full-up "test as you fly" scenarios; each will be staged to affect future milestone reviews. This particular mission makes maximum use of available inventory, while simulating the mass properties of hardware that will not be available until the Ares I-2 test flight three years later. The flight manifest included at the end of the paper will include two suborbital demonstrations, which will be supplemented by at least two orbital verification tests and one automated mission flight, before Ares 1/Orion begins crewed operations in 2014.

\section{References}

\footnotetext{
${ }^{1}$ National Aeronautics and Space Administration. The Vision for Space Exploration. February 2004.

${ }^{2}$ National Aeronautics and Space Administration. NASA's Exploration Systems Architecture Study Final Report. NASA-TM-2005-214062. November 2005.
} 
${ }^{3}$ Braukus, Mike, and Beth Dickey, "NASA's Exploration Systems Progress Report." NASA.gov, 1 September 2006, URL: http://www.nasa.gov/home/hqnews/2006/sep/HQ 06310 exploration status.html. 